\title{
Effect of heparin on plasma free fatty acid concentrations after acute myocardial infarction
}

\author{
RUDOLPH A RIEMERSMA, ROBERT LOGAN, DOUGLAS C RUSSELL, HOWARD J \\ SMITH,† JAMES SIMPSON, $¥$ MICHAEL F OLIVER \\ From Cardiovascular Research Unit, Departments of Cardiology and Medicine, University of Edinburgh, Edinburgh
}

SUMMARY Free fatty acid concentrations in plasma measured after in vivo heparinisation are often overestimated because of ex vivo lipolysis of variable degrees. A new method has been developed using immediate extraction of blood which obviates this and shows that the true rise in plasma free fatty acid concentration after heparin in ambulant ward patients and in patients with acute myocardial infarction is less than previously reported. The small rise in plasma free fatty acid concentration after heparin is unlikely to have adverse metabolic effects in most patients during acute myocardial infarction.

In addition to its anticoagulant action heparin has the effect of releasing several lipolytic enzymes into the circulation. ${ }^{1}$ These act on circulating triglycerides and phospholipids to release free fatty acids and result in a raised level of plasma free fatty acid concentration. This may have an adverse effect on patients with acute myocardial infarction, as an association has been shown between raised plasma free fatty acid concentrations, serious ventricular arrhythmias, and poor prognosis. ${ }^{2-4}$ Increments in plasma free fatty acid concentration after heparin in man have been reported as varying between 750 and $1100 \mu \mathrm{mol} / 1 . .^{5} 6$ Recorded values may be overestimated, however, in view of continuing ex vivo lipolysis before extraction.

The extent of this problem has been assessed by developing a technique of free fatty acid analysis after immediate whole blood extraction to eliminate ex vivo lipolysis, and determining the true heparin-induced rise in plasma free fatty acid concentration in ambulant ward patients and in patients after acute myocardial infarction. Data are compared with those obtained by plasma extraction techniques.

\section{Methods}

The time course of plasma free fatty acid concentrations after the intravenous administration of heparin

^Present address: Hutt Hospital, Lower Hutt, New Zealand.

tPresent address: ICI, Alderley Park, Macclesfield, Cheshire SK10 4TG.

¥Present address: MRC Brain Metabolism Unit, Edinburgh EH8 9JZ.

This investigation was supported by the British Heart Foundation and Evans Biologicals Limited.

Accepted for publication 18 May 1982
12500 international units (IU) was examined in three groups of patients. The first group (randomly selected general ward patients) consisted of nine men and one woman, aged 42 to 63 years. Their weights were between 49 and $99 \mathrm{~kg}$. The patients were studied after overnight fasting. All except one were ambulant and one had known ischaemic heart disease.

The second $(n=10)$ and third $(n=10)$ groups consisted of patients who had had an acute myocardial infarction, and were admitted to the coronary care unit of the Royal Infirmary, Edinburgh. There were 17 men and three women (aged 38 to 69 years). The diagnosis was considered established if the criteria recommended by the World Health Organisation were fulfilled. Patients with a history of bleeding disorders, those in cardiogenic shock (systolic blood pressure $<90 \mathrm{mmHg}$ ), or those requiring pacing or antiarrhythmic treatment were excluded, as were those on beta blockers or antilipolytic agents.

In a pilot study the effect of intravenous heparin $(10000$ IU) was examined on ex vivo lipolysis in eight $\stackrel{N}{\circ}$ ambulant ward patients at peak lipaemia approximately two hours after lunch.

Informed consent was obtained from all patients. The study was approved by the local ethical committee.

\section{PROCEDURE}

The same procedure was followed in each group of $\frac{T}{\circ}$ patients. After insertion of a cannula in the ante- $\mathbb{D}$ cubital vein, blood samples were taken for estimation of plasma triglyceride and free fatty acid concentrations, both 5 minutes and immediately before 
administration of 12500 IU heparin intravenously and for estimation of plasma free fatty acid concentrations at five, 10,15,30, 45, 60, and 90 minutes after administration of heparin.

Blood samples were processed for free fatty acid estimations in three ways: (1) from one aliquot of the blood sample free fatty acids were extracted immediately without centrifugation using a newly developed method (see laboratory methods); (2) from another aliquot free fatty acids were extracted immediately after separation of plasma and blood cells by a short centrifugation at room temperature, with a four minute delay; (3) another aliquot of the sample was processed using our standard laboratory free fatty acid procedure (20 minute delay).

\section{LABORATORY PROCEDURES}

Plasma free fatty acid concentrations were determined using a titrimetric method. ${ }^{7}$ To avoid lipolysis in blood samples taken from subjects given heparin, during blood cell separation and processing leading to artificially high plasma free fatty acid concentrations, a new method was developed. ${ }^{8}$ Free fatty acids were immediately extracted into $\mathrm{n}$-heptane from a whole blood sample $(0.75 \mathrm{ml})$, as described for plasma samples. ${ }^{7}$ Plasma and red cell membrane phospholipids were removed from a $2.0 \mathrm{ml}$ aliquot of the extract by selective adsorption to $200 \mathrm{mg}$ silicic acid. 9 The phospholipid free extract was evaporated under a stream of nitrogen in a heating block set at $60^{\circ} \mathrm{C}$. The fatty acids were redissolved in $3 \mathrm{ml}$ chloroform-n-heptane 8:7 ( $\mathrm{vol} / \mathrm{vol}$ ) and converted into their ${ }^{63} \mathrm{Ni}$-salts ${ }^{10}$ by addition of $200 \mu \mathrm{l}$ triethaolamine stabilised ${ }^{63} \mathrm{Ni}$ solution in $\mathrm{KBr}$. Final concentrations: triethanolamine $7.5 \%$ (vol/vol); $\mathrm{KBr} 40.5 \%$ (wt/vol); $\mathrm{Ni}\left(\mathrm{NO}_{3}\right)_{2} 0.5 \mathrm{mmol} /$; 63Ni specific activity (NBS 1, Amersham International) $4 \mathrm{mCi} / \mathrm{mmol}$. After vigorous mixing for 15 to 20 seconds, followed by a short centrifugation ( 5 minutes at $1500 \mathrm{~g}$ ) to separate the water and chloroform-heptane phases, the radioactive Ni-fatty acid salts in $1 \mathrm{ml}$ of the upper chloroform-heptane phases were analysed by liquid scintillation counting using $9 \mathrm{ml}$ liquid scintillant (NE 260, New England Nuclear). The method was calibrated using $99^{+} \%$ pure palmitic acid standards (British Drug House, Poole) dissolved in heptane, and taken through the extraction procedure.

The concentrations of fatty acids in blood extracts were expressed in terms of plasma concentrations, using a factor based on the packed cell volume, determined in quadruplicate using a Hawksley micro-haematocrit centrifuge.

The extraction of albumin-bound ${ }^{3} \mathrm{H}$-palmitate added to eight different human blood samples was on average $100 \cdot 0 \pm 1 \cdot 7 \%$ (mean \pm SEM). More than $94 \%$ of pure lecithin $(2.75 \mathrm{mg} / \mathrm{ml}$ in heptane) was selec- tively absorbed to silicic acid. Blood lactate concentrations of less than $3.2 \mathrm{mmol} / 1$ do not interfere; interferences by higher concentration were not examined.

The precision of the method was assessed by repeatedly (10 times) analysing a palmitic acid standard $(400 \mu \mathrm{mol} / \mathrm{l})$ on two occasions. The coefficients of variations were 6 and $8.5 \%$, respectively.

No statistically significant differences were found when results of the whole blood method were compared with the standard plasma free fatty acid titrimetric procedure in non-heparinised subjects, both when plasma free fatty acid concentrations are raised (Fig. 3) or within normal range (Fig. 2 and 4), p>0.05 paired $t$ test.

Plasma triglycerides were determined in extracts $(0.5 \mathrm{ml})$, prepared immediately after collection, by an automated fluorimetric method. ${ }^{11}$ Appropriate corrections for interference by free glycerol were made. The coefficient of variation of the method was $2 \%$.

In patients with acute myocardial infarction, the vectorcardiogram was monitored in order to assess changes in ST segments as described previously. ${ }^{12}$

Results are expressed as mean \pm SEM. The effect of heparin on plasma free fatty acid concentrations and differences between results obtained with the three free fatty acid methods were analysed using a paired Student's $t$ test. $P>0.05$ was considered statistically nonsignificant.

\section{Results}

\section{EX VIVO LIPOLYSIS AFTER HEPARIN} ADMINISTRATION

Ex vivo lipolysis indicated by a rise in plasma free fatty acid concentrations was observed in blood samples obtained 15 minutes after the administration of $10000 \mathrm{IU}$ heparin to eight ambulant ward patients at peak lipaemia approximately two hours after lunch. Plasma triglyceride concentrations before administration of heparin ranged from 1.3 to 4.4 ; mean $\pm S D$ : $3.1 \pm 1.0 \mathrm{mmol} / \mathrm{l}$. When blood samples were incubated at room temperature plasma free fatty acid concentrations rose at a rate of approximately $30 \mu \mathrm{mol} / \mathrm{l}$ per min (Fig. 1). Cooling of blood did not prevent the increase in plasma free fatty acid concentration completely and in particular the initial rise was not abolished.

\section{EFFECT OF HEPARIN ON IN VIVO PLASMA FREE}

\section{FATTY ACID CONCENTRATIONS}

An intravenous injection of heparin (12 $500 \mathrm{IU}$ ) was given after overnight fasting to 10 general ward patients. Plasma free fatty acid concentrations, determined in whole blood extracts, increased in a time dependent manner from $802 \pm 104$ (range 365 to 1327) to a maximum of $993 \pm 95 \mu \mathrm{mol} / \mathrm{l}$ (range 548 to 1368) and returned to pre-heparin values approxi- 


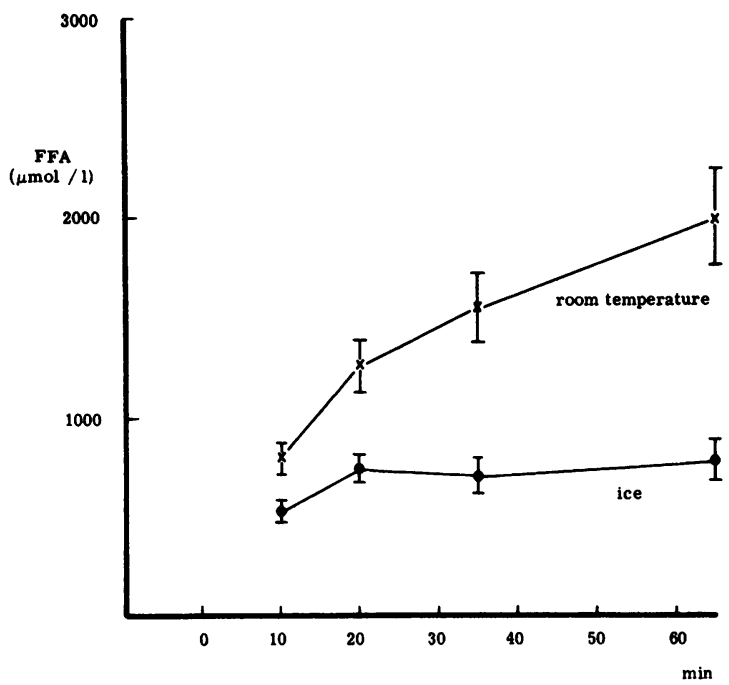

Fig. 1 Effect of temperature on ex vivo lipolysis in blood samples from postprandial subjects given heparin. Comparison of plasma free fatty acid concentrations in blood samples, taken 15 minutes after 10000 IU heparin intravenously. (O) Samples stored on ice; (ヤ) stored at room temperature. Plasma free fatty acids were extracted at the indicated time afier collection. Means of seven to eight obseroations $\pm S E M$. Difference between all pairs is significant (paired $t$ test, $p<0.01$ ).

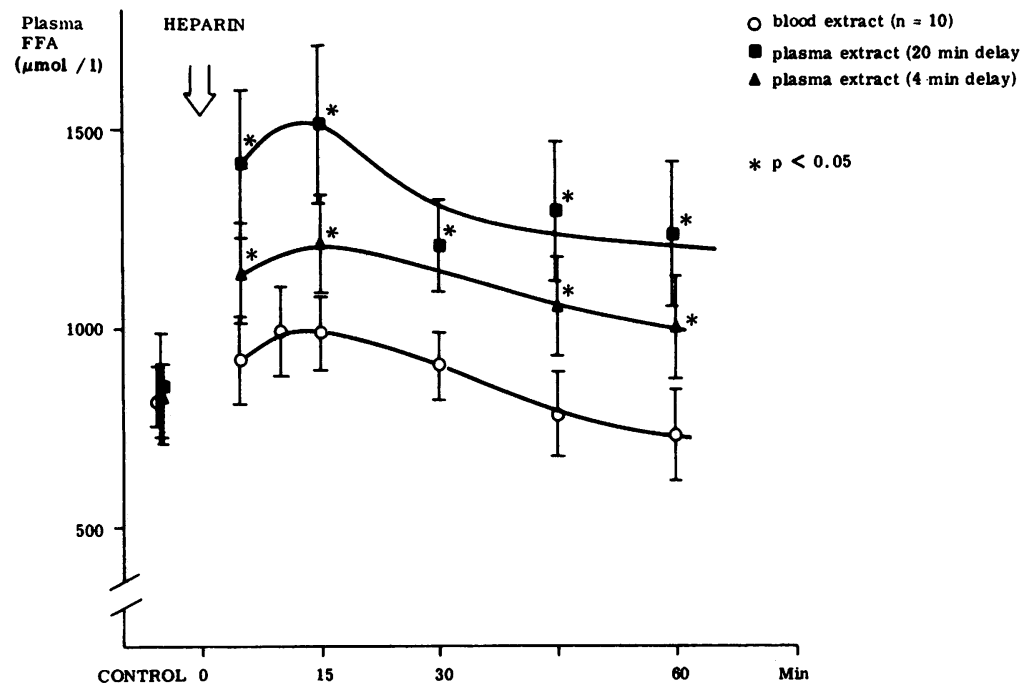

Fig. 2 The effect of heparin (12500 IU intravenously) on plasma free fatty acid concentrations in 10 general ward patients after overnight fasting. Comparison of free fatty acid methods: $O$ measured in whole blood extracts; $\Delta$ measured titrimetrically in plasma samples extracted within four minutes of blood collection; measured titrimetrically (20 minutes delay).

Note that before heparin was given free fatty acid concentrations were similar, but after heparin the methods gave significantly different results $(n=8-10$, paired $t$ test $0.01<p<0.05$ ). 


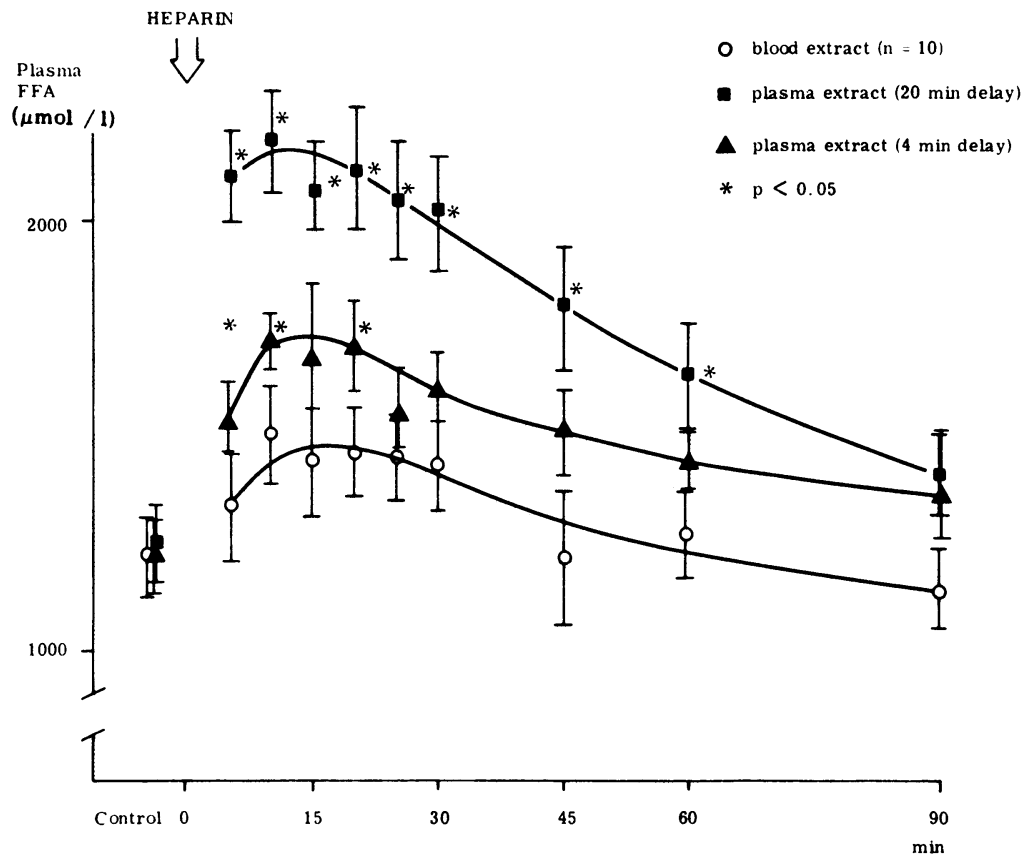

Fig. 3 The effect of heparin (12 500 IU intravenously) on plasma free fatty acid concentrations in 10 patients with acute myocardial infarction $\left(<6 \frac{1}{2}\right.$ hours after onset of symptoms). Symbols as in Fig. 2.

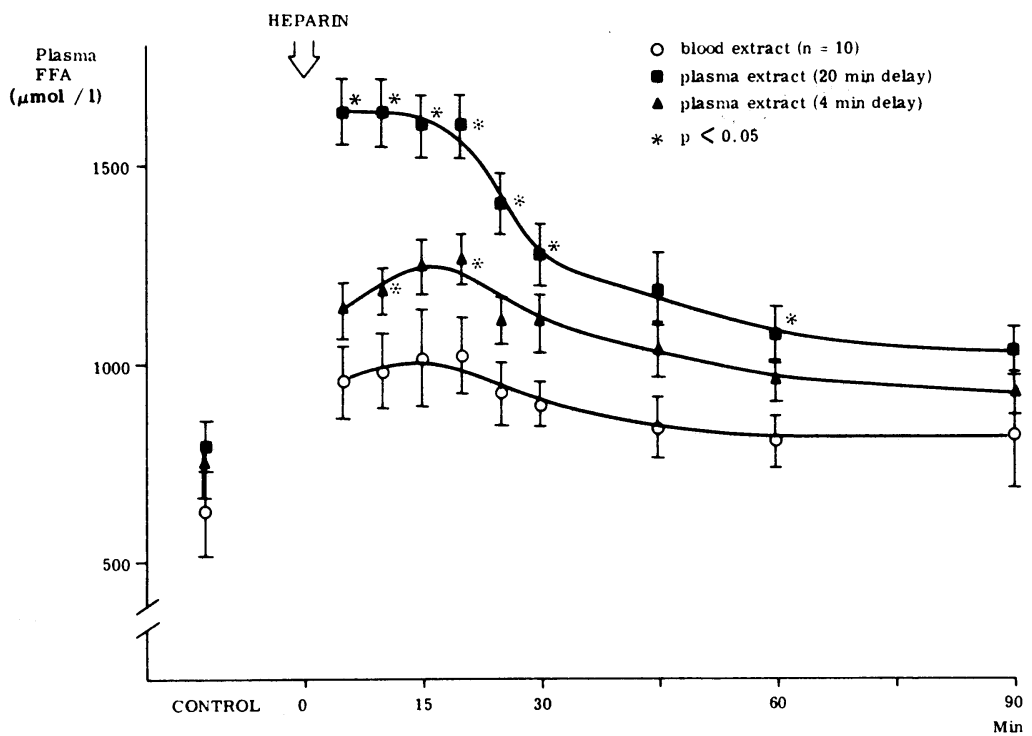

Fig. 4 The effect of heparin ( 12500 IU intravenously) on plasma free fatty acid concentrations in 10 patients with acute myocardial infarction (between 16 and 22 hours after onset of symptoms). Note mean plasma free fatty acid concentrations before heparin are lower than in patients with acute myocardial infarction studied earlier (Fig. 3). Symbols as in Fig. 2. 
mately 45 minutes later (Fig. 2).

Plasma free fatty acid concentrations determined by both whole blood and rapid plasma extraction (four minutes delay) before administration of heparin were not significantly different. After administration, titrimetrically measured levels of heparin were consistently higher than those measured by the whole blood extraction method. Differences in free fatty acid levels recorded between the two methods were significant at all sampling periods after heparin (paired $t$ test, $0.01<\mathrm{p}<0.05$ ).

When the extraction of plasma samples was delayed by 20 minutes, plasma free fatty acid concentrations were even higher. The increase in plasma free fatty acid concentrations 15 minutes after heparin over the pre-heparin value was then $693 \mu \mathrm{mol} / \mathrm{l}$. This represents a $260 \%$ overestimation of plasma free fatty acid concentrations, when allowance is made for the "true" in vivo increase in the concentrations of plasma free fatty acids of $191 \mu \mathrm{mol} / \mathrm{l}$ (Fig. 2). This overestimation was closely related to the initial plasma triglyceride concentrations $(r=0.82, n=8, p<0.01)$.

\section{EFFECT OF HEPARIN ON IN VIVO PLASMA FREE FATTY ACID CONCENTRATIONS DURING ACUTE MYOCARDIAL INFARCTION}

Plasma free fatty acid concentrations were raised in all patients admitted to the coronary care unit within six and a half hours after onset of symptoms of acute myocardial infarction: $1232 \pm 91 \mu \mathrm{mol} / \mathrm{l}$ (upper normal limit is $900 \mu \mathrm{mol} / \mathrm{l}$ ) (Fig. 3).

Before administration of heparin plasma free fatty acid values determined by all three methods did not differ significantly. As was observed in general ward patients, plasma free fatty acid concentrations after heparin were overestimated with the standard titrimetric method. The new method on whole blood extracts showed a true increment of $334 \pm 73 \mu \mathrm{mol} / 1$.

In 10 patients the effect of giving heparin was examined (12500 IU) when plasma free fatty acid concentrations had passed their peak. Plasma free fatty acid levels returned to within the normal range in all but three patients studied between 16 and 22 hours after onset of symptoms. After giving heparin plasma free fatty acid concentrations rose from $658 \pm 80$ to $983 \pm 94 \mu \mathrm{mol} / 1$ within 10 minutes (Fig. 4). This increment was similar to that observed in patients with acute myocardial infarction studied early after the onset of symptoms. Titrimetric analysis overestimated plasma free fatty acid concentrations after heparin also in these patients (Fig. 4).

In six patients with acute myocardial infarction to whom heparin was administered within six and a half hours after the onset of symptoms ST segment vector magnitude was monitored and showed a gradual decline with respect to time before the administration
Table Effect of heparin on ST segment vector and plasma free fatty acid concentrations in six patients with acute myocardial infarction ( $<6 \frac{1}{2}$ hours)

\begin{tabular}{llll}
\hline & Control & Heparin \\
\cline { 3 - 4 } & & At FFA max & 60 min \\
\hline $\begin{array}{c}\text { Free fatty acid } \\
\text { concentration } \\
(\mu \text { mol } / /)\end{array}$ & $1243 \pm 132$ & $1613 \pm 96$ & $1372 \pm 132$ \\
$\begin{array}{c}\text { ST segment } \\
\text { vector }(\mathrm{mV})\end{array}$ & $0.18 \pm 0.02$ & $0.17 \pm 0.03$ & $0.17 \pm 0.02$ \\
\hline
\end{tabular}

^Determined in whole blood extracts.

of heparin. This trend was not altered during the course of a transient heparin-induced increase in plasma free fatty acid concentrations (Table).

\section{Discussion}

This study shows that the generally accepted procedures for the estimation of plasma free fatty acid concentrations lead to serious overestimations in subjects given heparin, as a result of in vitro lipolysis. Unless precautions are taken to prevent lipolysis in blood specimens between withdrawal and extraction, artificially high levels are obtained. This observation applies to blood taken from patients with and without acute myocardial infarction, who had been given heparin. In view of the high in vitro lipolytic rate $(4 \% / \mathrm{min}$ at room temperature), it was decided to extract whole blood specimens without processing. This new method will be valuable for studies where accurate measurements of plasma free fatty acid concentrations are imperative.

Using this method we have now shown that in convalescent patients and patients with acute myocardial infarction plasma free fatty acid levels remained well within the physiological range, though plasma free fatty acid concentrations rose after the administration of heparin. The larger rises previously reported 56 were mostly the result of delay in denaturing lipolytic enzymes in collected blood samples; in one of these studies $^{5}$ plasma triglyceride levels were not measured and it is possible that higher free fatty acid concentrations resulted from higher circulating triglyceride levels. Other studies showing higher plasma free fatty acid concentrations after administration of heparin to patients with coronary artery disease support the view that this error is common. ${ }^{13} 14$

Assessment of "true" plasma free fatty acid concentrations is necessary for understanding the relative importance of the proposed detrimental and beneficial effects of heparin on the ischaemic myocardium. Raised plasma free fatty acid concentrations have been associated with the development of serious ventricular arrhythmias in patients with acute myocardial 
infarction..$^{2-4}$ An hypothesis was proposed that this effect of raised plasma free fatty acid concentrations might lead to serious ventricular arrhythmias as a result of increasing oxygen requirements in the presence of ischaemia or a detergent effect or relative impairment of myocardial glucose metabolism. ${ }^{15}$ Raised plasma free fatty acid concentrations exert a negative inotropic effect on the hypoxic or ischaemic myocardium, ${ }^{16} 17$ which could offset the increase in myocardial oxygen consumption caused by the metabolic effects of free fatty acids. The relatively small "true" rise in plasma free fatty acid concentrations may explain why in our study and in previous studies heparin did not exacerbate ST segment abnormalities ${ }^{13} 1418$ or increase myocardial oxygen consumption in patients with acute infarction. ${ }^{14} 19$

Heparin may have a protective role in addition to that against venous thromboembolism, ${ }^{20}$ by reducing blood viscosity and pulmonary oedema. ${ }^{21}$ Recently, it has been claimed to be more effective than beta blockade on short term prognosis. ${ }^{22}$ If used in orthodox doses, provided there is no hyperlipidaemia, the metabolic effects on the ischaemic myocardium should be small and it should be safe in most patients when given several hours after the onset of symptoms. Its safety during the most acute phase has yet to be examined formally. In addition, its safety in the presence of hyperlipidaemia must be investigated.

\section{References}

1 Tan MH. The lipoprotein lipase system: new understandings. Can Med Assoc $\mathcal{F}$ 1978; 118: 675-80.

2 Oliver MF, Kurien VA, Greenwood TW. Relation between serum-free-fatty-acids and arrhythmias and death after acute myocardial infarction. Lancet 1968; i: 710-5.

3 Gupta DK, Young R, Jewitt DE, Hartog M, Opie LH. Increased plasma-free-fatty acid concentrations and their significance in patients with acute myocardial infarction. Lancet 1969; ii: 1209-13.

4 Carlstrom S, Christensson B. Plasma glycerol concentration in patients with myocardial ischaemia and arrhythmias. Br Heart f 1971; 33: 884-8.

5 Nelson PG. Effect of heparin on serum free fatty acids, plasma catecholamines, and the incidence of arrhythmias following acute myocardial infarction. $\operatorname{Br}$ Med F 1970; iii: 735-7.

6 Russo JV, Friesinger GC, Margolis S, Ross RS. Heparin and ventricular arrhythmias after myocardial infarction. Lancet 1970; ii: 1271-5.

7 Trout DL, Estes EH Jr, Friedberg SJ. Titration of free fatty acids of plasma: a study of current methods and a new modification. 7 Lipid Res 1960; 1: 199-202.
8 Riemersma RA. Metabolic aspects of acute myocardial ischaemia. University of Edinburgh: Ph.D. Thesis, 1979.

9 Laurell S, Tibbling G. Colorimetric micro-determination of free fatty acids in plasma. Clin Chim Acta 1967; 16: 57-62.

10 Ho RJ. Radiochemical assay of long-chain fatty acids using ${ }^{63} \mathrm{Ni}$ as tracer. Anal Biochem 1970; 36: 105-13.

11 Kessler G, Lederer H. Fluorimetric triglyceride procedure as used by the Lipid Laboratory at the Centre for Disease Control. In: Skeggs L, ed. Automation in analytical chemistry. New York: Mediad, 1966: 341-4.

12 Russell DC, Oliver MF. Effect of antilipolytic therapy on ST-segment elevation during myocardial ischaemia in man. Br Heart $\mathcal{F}$ 1978; 40: 117-23.

13 Dagenais GR, Jalbert B. Effects of free fatty acid increase on angina threshold during atrial pacing (abstract). Circulation 1975; 51/52, suppl II: 128.

14 Simonsen S, Kjekshus JK. The effect of free fatty acids on myocardial oxygen consumption during atrial pacing and catecholamine infusion in man. Circulation 1978; 58: 484-91.

15 Kurien VA, Oliver MF. A metabolic cause for arrhythmias during acute myocardial hypoxia. Lancet 1970; i: 813-5.

16 Henderson AH, Most AS, Parmley WW, Gorlin R, Sonnenblick EH. Depression of myocardial contractility in rats by free fatty acids during hypoxia. Circ Res 1970; 26: 439-49.

17 Liedtke AJ, Nellis S, Neely JR. Effects of excess free fatty acids on mechanical amd metabolic function in normal and ischemic myocardium in swine. Circ Res 1978; 43: 652-61.

18 Saliba MJ, Kuzman WJ, Marsh DG, Lasry JE. Effect of heparin in anticoagulant doses on the electrocardiogram and cardiac enzymes in patients with acute myocardial infarction. Am f Cardiol 1976; 37: 605-7.

19 Rogers WJ, McDaniel HG, Moraski RE, Rackley CE, Russell RO Jr. Effect of heparin-induced free fatty acid elevation on myocardial oxygen consumption in man. Am f Cardiol 1277; 40: 365-72.

20 Warlow W, Terry G, Kenmure ACF, Beattie AG, Ogston D, Douglas AS. A double-blind trial of low doses of subcutaneous heparin in the prevention of deep-vein thrombosis after myocardial infarction. Lancet 1973; ii: 934-6.

21 Jacques LB. Heparins-anionic polyelectrolyte drugs. Pharmacol Rev 1979; 31: 99-166.

22 Gross H, Vaid AK, Levine HS, Hasson J. Anticoagulant therapy in myocardial infarction. Am $\mathcal{F}$ Med 1972; 52: $421-4$.

Requests for reprints to Dr Rudolph A Riemersma, Cardiovascular Research Unit, University of Edinburgh, Hugh Robson Building, George Square, Edinburgh EH8 9XF. 